\title{
Integrated Fire Management For Preventing Mega-Fires Occurrences In Estação Ecológica Serra Geral Do Tocantins, Jalapão, Brazil
}

\author{
Ana Carolina Sena Barradas ${ }^{1}$, Marco Assis Borges ${ }^{1}$ e Máximo Menezes Costa 1 .
}

\begin{abstract}
${ }^{1}$ Instituto Chico Mendes de Conservação da Biodiversidade (ICMBio).
E-mails: carolina.barradas@icmbio.gov.br, marco.borges@icmbio.gov.br, maximo.menezes@icmbio.gov.br
\end{abstract}

\begin{abstract}
This research describes the evolution of fire management at Serra Geral do Tocantins Ecological Station (SGTEE) and how it influences mega fires occurrences in this protected area. The method of work involved bibliographic review, documentary analysis and personal experience, since all authors work at EESGT. Two fire management approaches were identified in the protected area: one focused on fire exclusion (2001 to 2012) and the other on fire management (2014 - current). We noticed that the period of fire exclusion led to fuel accumulation and continuity favoring large wildfires occurrences. Mega fires events were registered in 2010, 2012 and 2014 burning, respectively, 80.000, 107.000 and 88.000 hectares. The SGTEE faced the challenge of formally changing management paradigms by assuming that adaptive and integrated fire management can ensure the effective protection of its socio-biodiversity. Since 2015, when fire use has been expanded through prescribed burns and participatory management agreements with traditional communities, no mega fires have been recorded at PA (the largest event recorded in 2018 was only 3.000 hectares). The current experience of fire management in the SGTEE reveals that it is possible to revert scenarios of recurrence of mega fires at the late dry season, common in the Cerrado, and transform socioenvironmental conflicts into opportunities for knowledge integration and participatory management. It also inspire the revision of traditional paradigms in the conservation of Brazilian biodiversity in savannas protected areas.
\end{abstract}

Keywords: mega-fires; integrated fire management; protected areas; Cerrado; fire management; wildfire prevention. 